\title{
Engineered Keratinized Oral Mucosa Decreased C. albicans Transition Through the Production of Keratins 10, 14, 16, and 19 by Oral Epithelial Cells
}

\author{
Andrew Zakrzewski and Mahmoud Rouabhia ${ }^{*}$
}

Groupe de Recherche en Ecologie Buccale, Faculté de Médicine Dentaire, Université Laval, Québec, QC, Canada G1K 7 P4

\begin{abstract}
The aim of this study was to evaluate the link between Candida albicans growth and dimorphism and the production of keratins by oral epithelial cells. Various culture models (monolayer and non-keratinized and keratinized engineered human oral mucosa) were produced and used for this purpose. Cell morphology, tissue structure, and the transition of $C$. albicans were assessed following cell and tissue infections. Keratin production by epithelial cells exposed to $C$. albicans was evaluated by Western blotting. Following contact with $C$. albicans, epithelial cells in the monolayer cultures showed differentiating phenotypes. Compared to the keratinized tissue, the non-keratinized mucosa displayed visible disorganization. The transition of $C$. albicans from blastospore to hyphal form was significantly lower in the keratinized oral mucosa model. This was correlated with the high levels of differentiating (K10) and proliferating (K14, K16, and K19) keratins in the keratinized tissue, suggesting that tissue stratification contributes to controlling C. albicans pathogenicity via keratin production. Thus, the transition of $C$. albicans from blastospore to hyphal form may be linked to keratin production. This may ultimately have implications in the control of oral candidiasis as well as in denture design to prevent denture stomatitis.
\end{abstract}

Keywords: Epithelial cells, Candida albicans, keratins, yeast transition.

\section{INTRODUCTION}

Oral candidiasis is an opportunistic infection that is common among the elderly, particularly those who wear dentures, and remains largely undiagnosed. Denture stomatitis is the term used for the chronic inflammation of denturebearing mucosa and is characterized by erythema of the palate and alveolar ridges [1].

The etiology of denture stomatitis is multifactorial, involving both local and systemic predisposing factors [2, 3]. Microbial plaque accumulation on the intaglio surface of removable dentures plays a critical role by promoting a switch from commensal to pathogenic oral flora [4]. Microbial communities attach themselves to different surfaces and grow in the form of biofilms located on human tissue and as a variety of biomaterials including acrylic dentures, causing morbidity, such as denture stomatitis. Numerous studies have reported the association between $C$. albicans and denture stomatitis $[5,6]$. Oral candidiasis associated with bioprosthetic surfaces is by far the most common fungal infection in denture wearers [1]. The denture-palate interface offers a unique ecological niche for microorganism colonization because of the relatively anaerobic and acidic environment that favors yeast proliferation [4]. Hence, dentures act as reservoirs that harbour Candida spp. within a mixedspecies bacterial biofilm.

Although the exact pathogenesis is still unclear, a combination of trauma and Candida infection has been suggested as etiologic factors [7]. Inflammatory papillary

*Address correspondence to this author at the Faculté de Médecine Dentaire, Pavillon de Médecine Dentaire, Local 1728, Université Laval, Québec, QC, Canada G1K 7P4; Tel: (418) 656-2131, Ext. 16321; Fax: (418) 6562861; E-mail: Mahmoud.rouabhia@fmd.ulaval.ca hyperplasia of the palate (IPHP) is related to ill-fitting dentures, poor denture hygiene and wearing dentures $24 \mathrm{~h}$ a day. Its frequency in denture-wearing elderly patients varies between 5 and $20 \%$. Old dentures are associated more frequently with IPHP than are newer ones, independent of denture quality [8].

The histopathological appearance of IPHP exhibits papillary projections covered by keratinized stratified squamous epithelium. The underlying connective tissue varies from loose and edematous to densely collagenized and it is usually infiltrated by chronic inflammatory cells consisting mainly of lymphocytes and plasma cells [9].

Various factors are thought to contribute to the virulence of $C$. albicans. These include adhesion to host tissue, the ability to undergo reversible morphogenetic transitions between budding (yeast) and filamentous (hyphae and pseudohyphae) growth forms, the secretion of extracellular hydrolases, and the rapid switching between different phenotypic forms $[10,11]$. The contribution of yeast-hyphae morphogenesis to $C$. albicans virulence has been hotly debated [12, 13]. However, it is clear that hyphal development is closely associated with tissue invasion $[12,13]$.

Host defenses against Candida infections are complex, involving both cellular and humoral factors. Cell-mediated immunity (CMI) is thought to be the predominant host defense mechanism against mucosal candidiasis [14]. In addition to their role of anti-Candida CMI in the oral mucosa, epithelial cells may be involved in the innate immunity against bacterial and yeast infections via an active inflammatory process $[15,16]$.

Epithelia protect the underlying tissue from environmental influences, such as physical damage and bacterial 
infection, to maintain homeostasis. Differentiation and morphology are used to classify oral epithelial tissue into two broad categories: keratinizing stratified squamous epithelia, such as the palate and the gingival tissue within the oral cavity, and non-keratinizing stratified epithelia, such as the buccal oral mucosa and the oesophagus [17, 18]. A critical aspect of keratinizing stratified epithelia is that the cells undergo a terminal differentiation program that results in the formation of a mechanically resistant surface composed of cornified cells filled with keratin filaments. This keratin envelope protects the underlying epithelial cells $[19,20]$.

Keratins, the predominant cytoskeletal component in keratinizing stratified epithelia, are divided into two families: Type I, containing acidic proteins (keratins K9-K20) and Type II, containing basic or neutral proteins (keratins K1K8). Various keratins are distributed throughout the different strata of the epithelium. Within stratified epithelia, the keratin pair $\mathrm{K} 5 / \mathrm{K} 14$ is expressed in the basal proliferative layer. Keratin 19 is expressed in basal cells of non-keratinizing epithelia. K6 and K16 are constitutively expressed in different stratified epithelia, including the tongue, palate, gingiva, and esophagus [19, 20]. Differentiating suprabasal cells of gingival tissue express keratins $\mathrm{K} 1$ and K10. In buccal mucosa tissue, keratins $\mathrm{K} 1$ and $\mathrm{K} 10$ are expressed in a sporadic fashion [21]. The presence of $\mathrm{K} 1$ and $\mathrm{K} 10$ transcripts may be involved in the rapid response of buccal epithelium to various stimuli that put a heavier functional demand on the tissue [21].

Modified keratin distribution (expression) may be correlated with changes in epithelial cell differentiation and barrier protection function. Dentures, for example, cause profound alterations to the environmental conditions. Palatal keratinization is notably lower in the epithelium under and around partial and complete dentures [22, 23]. In addition, the epithelium thickens due to an increase in its constituent cell layers, while the degree of inflammation appears to be inversely proportional to the degree of keratinization [24, 25]. A reduced keratinization is then likely to promote $C$. albicans adhesion by providing the ideal conditions for it to proliferate and to switch from blastospore to hyphal form, which in turn may enable $C$. albicans to penetrate into the tissue, resulting in deep infection. The aims of this study were thus (A) to investigate the effect of keratins on C. albicans transition from blastospore to hyphal form and (B) to determine the effect of $C$. albicans on the production of keratins $\mathrm{K} 10, \mathrm{~K} 14, \mathrm{~K} 16$, and $\mathrm{K} 19$ which are known to be involved in oral epithelial cell differentiation and proliferation.

\section{EXPERIMENTAL PROCEDURES}

\section{Oral Epithelial Cell Isolation and Culture}

Small samples of palatal mucosa were collected from gingival graft patients with their informed consent. The biopsies were treated with thermolysin $(500 \mu \mathrm{g} / \mathrm{ml})$ to separate the epithelium from the lamina propria [26]. Epithelial cell suspensions were obtained by treating the tissue with a $0.05 \%$ trypsin-0.01 M EDTA solution. Freshly isolated epithelial cells $\left(9 \times 10^{3} / \mathrm{cm}^{2}\right)$ were cultured in a 3: 1 mixture of Dulbecco's modified Eagle's medium-Ham's F12 medium (DMEH) (Invitrogen Life Technologies, Burlington, ON, Canada) supplemented with $24.3 \mu \mathrm{g} / \mathrm{ml}$ adenine, $10 \mu \mathrm{g} / \mathrm{ml}$ human epidermal growth factor (Chiron Corp., Emeryville, CA, USA), $0.4 \mu \mathrm{g} / \mathrm{ml}$ hydrocortisone (Calbiochem, La Jolla, CA, USA), $5 \mu \mathrm{g} / \mathrm{ml}$ bovine insulin, $5 \mu \mathrm{g} / \mathrm{ml}$ human transferrin, $2 \times 10^{-9} \mathrm{M} 3,3^{\prime}$, 5', triiodo-L-thyronine, $10^{-10} \mathrm{M}$ cholera toxin (Schwarz/Mann, Cleveland, OH, USA), $100 \mathrm{U} / \mathrm{ml}$ penicillin, $25 \mu \mathrm{g} / \mathrm{ml}$ gentamicin (Schering, Pointe-Claire, QC, Canada), and 5\% fetal calf serum (NCS, fetal clone II, Hyclone, Logan, UT, USA). Following characterization [26], the oral epithelial cells were cultured, resulting in a large number of cells. Passage-two epithelial cells were used for this study. Cells isolated from the same biopsy (donor) were used to produce monolayer cultures, non-keratinized engineered human oral mucosa (nkEHOM), and keratinized engineered human oral mucosa (kEHOM).

\section{Oral Fibroblast Isolation and Culture}

Once separated from the epithelium, the lamina propria was placed in a collagenase P solution $(0.125 \mathrm{U} / \mathrm{ml}$; Boehringer Mannheim, Laval, QC, Canada) for $45 \mathrm{~min}$ at $37^{\circ} \mathrm{C}$ to extract the fibroblasts. Isolated cells $\left(2 \times 10^{6}\right)$ were seeded in $75 \mathrm{~cm}^{2}$ flasks (Falcon, Becton Dickinson, Cockeysville, MD, USA) and grown in Dulbecco's modified Eagle's (DME) medium (Invitrogen Life Technologies) containing $5 \%$ fetal calf serum (Invitrogen Life Technologies), $100 \mathrm{IU} / \mathrm{ml}$ penicillin $\mathrm{G}, \quad 25 \mu \mathrm{g} / \mathrm{ml}$ streptomycin, and $0.5 \mu \mathrm{g} / \mathrm{ml}$ fungizone (Sigma-Aldrich Canada Ltd., Oakville, ON, Canada). Following culture, the fibroblasts were used for this study. The cells isolated from the same biopsy (donor) were used to produce nkEHOM and kEHOM.

\section{Preparation of Engineered Human Oral Mucosa}

Engineered human oral mucosa (EHOM) were produced as described previously [26]. Briefly, engineered lamina propria was produced by mixing bovine skin collagen (Sigma-Aldrich) with normal human oral fibroblasts $\left(1.5 \times 10^{6}\right.$ cells $)$. The mixture was poured into a Petri dish (35 $\mathrm{mm}$ in diameter) containing an anchorage to prevent collagen contraction. Tissue was grown in culture in $5 \%$ fetal calf serum supplemented with Dulbecco's modified Eagle medium. Four days later, the engineered lamina propria was seeded with oral epithelial cells $\left(9 \times 10^{4} / \mathrm{cm}^{2}\right)$ to obtain the EHOM. Tissue was grown until the epithelial cells reached confluence. To mimic the keratinized palatal mucosa tissue, EHOM were then raised to an air-liquid interface for 5 more days to allow the epithelium to stratify [27, 28]. Following this process, as we have shown previously, the EHOM was a well-organized and stratified tissue in which epithelial cells expressed proliferating keratins such as Ki-67, K14, and K19 and also differentiating keratin K10. In this model, the epithelial cells interacted with fibroblasts in the lamina propria by secreting basement membrane proteins such as laminin and type IV collagen [26].

\section{Candida albicans Growth}

A clinical C. albicans (Candida-associated stomatitis) isolate was used in this study [29]. The yeast was grown on Sabouraud dextrose agar (SAB, Becton-Dickinson, Sparks, $\mathrm{MD}$, USA) at $30^{\circ} \mathrm{C}$. For the $C$. albicans suspensions, one colony was used to inoculate $10 \mathrm{ml}$ of phytone-peptone (PP) medium (Becton-Dickinson) supplemented with $0.1 \%$ glucose. The culture was grown to the stationary phase for $18 \mathrm{~h}$ at $37^{\circ} \mathrm{C}$ in a shaking water bath. The blastoconidia were col- 
lected, washed with PBS, and enumerated using a hemacytometer [30]. The culture was adjusted to $10^{7} \mathrm{cells} / \mathrm{ml}$ and used to infect the tissue.

\section{Histological Analysis of Tissue Structure and Epithelial Cell Morphology}

Immediately following each contact period, the monolayer cultures were washed twice with PBS, observed under an optical microscope (Nikon Canada Inc, Mississoga, Ontario, Canada), and photographed. The non-infected and C. albicans-infected EHOMs were used for histological analysis. Biopsies were taken from each tissue, fixed with Bouin's solution, and embedded in paraffin. Thin sections $(4 \mu \mathrm{m})$ were stained with Masson's trichrome and mounted with a coverslip in 50\% glycerol mounting medium, observed under an optical microscope, and photographed. The figures are representative pictures of six different experiments.

\section{Count of $C$. albicans Hyphal Forms and Protein Extrac- tion from Epithelial Cells}

C. albicans $\left(10^{6} / \mathrm{cm}^{2}\right)$ was seeded onto an epithelial cell monolayer, nkEHOM and kEHOM (see Fig. (1)). The in- fected monolayer, EHOMs, and uninfected controls were cultured for 2, 4, 8, and 24 hours. Following each contact period, the culture media were collected from the monolayer and the EHOMs. The cells in the monolayer were detached, and the epithelia of the EHOMs were separated from the lamina propria and collected. The cells and epithelia were treated with lysis buffer. The transition of $C$. albicans was assessed using the culture media and the monolayer and EHOM lysates. Four aliquots were taken from each sample, rigorously mixed to separate as much as possible the clumps of fungal and basically hyphal forms, then placed in a hemacytometer and examined under an inverted microscope to count the blastospores and hyphae. We counted, as hyphae, the separate hyphal cells and cell units bounded by septa within a filament. More than two hundred blastospore and hyphal forms were counted from each sample. The percentage of $C$. albicans transition was calculated by dividing the number of hyphal forms by the total number of C. albicans cells. The results are expressed as the means \pm SD of eight different experiments and are given as the percentage of transition. The cell and epithelial lysates were also used to assess the effect of C. albicans on keratin (K10, K14, K16,
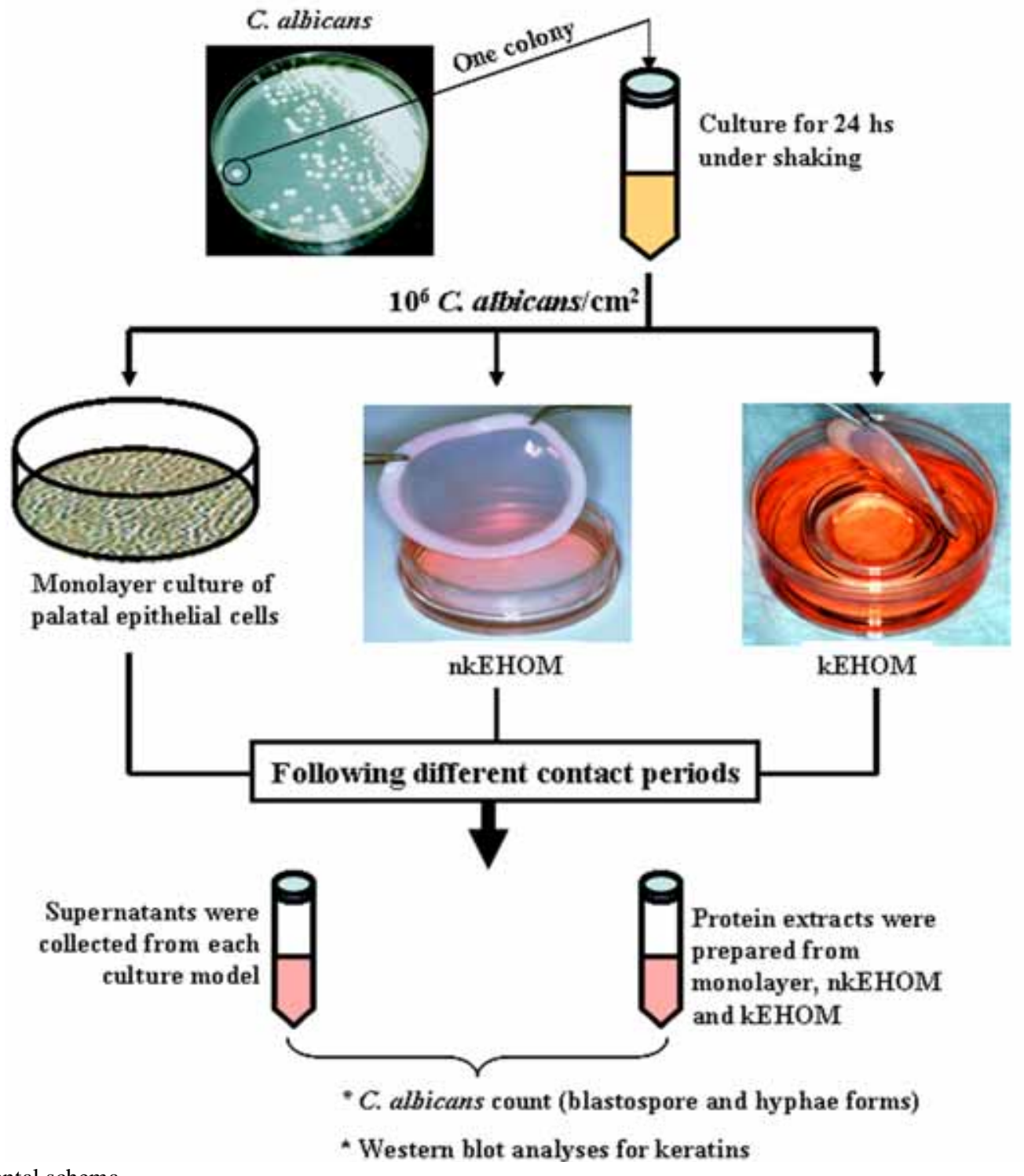

Fig. (1). Experimental schema. 
and K19) production by the epithelial cells by means of Western blotting.

\section{Western Blotting and Immunodetection of K10, K14, K1, and K19}

Western blotting was performed as described previously [31]. Protein extracts were prepared by solubilizing unstimulated and C. albicans-stimulated oral epithelial tissue in lysis buffer containing $1 \mathrm{mM}$ HEPES, $0.5 \%$ Nonidet P-40, $0.5 \mathrm{mM} \mathrm{MgCl} 2,0.1 \% \beta$-mercaptoethanol, $0.1 \%$ sodium dodecyl sulfate, $1 \mu \mathrm{g} / \mathrm{mL}$ aprotinin, $3 \mu \mathrm{g} / \mathrm{mL}$ pepstatin, and $0.2 \mathrm{mM}$ phenylmethylsulfonyl fluoride. Equal amounts of total protein were loaded onto an SDS-PAGE gel. Following electrophoretic separation, the proteins were transferred to a nitrocellulose membrane (Pall Gelman Laboratory, Ann Arbor, MI, USA) and blocked for $1 \mathrm{~h}$ with TBS-T (100 mM Tris, $\mathrm{pH} 7.5,0.9 \% \mathrm{NaCl}$ and $0.05 \%$ Tween 20 ) containing $5 \%$ bovine serum albumin. The membrane was incubated overnight at $4^{\circ} \mathrm{C}$ with mouse anti-human cytokeratin-10/13 (DE-K13), cytokeratin-14 (C-14), which is an affinitypurified goat polyclonal antibody, mouse anti-human cytokeratin 19 (A53/B/A2) monoclonal antibody (1: 200, Santa Cruz Biotechnology Inc., Santa Cruz, CA, USA) and mouse anti-human K16 (1: 200, MediCorp, Montréal, QC, Canada) monoclonal antibody. The membrane was washed ( $1 \times 15 \mathrm{~min}$ and $3 \times 5 \mathrm{~min})$ in TBS-T and incubated for $30 \mathrm{~min}$ at room temperature with the appropriate secondary horse peroxidase-labeled antibody (1: 1000, Amersham Biosciences, Buckinghamshire, UK). After washing with TBS-T ( $1 \times 15 \mathrm{~min}$ and $2 \times 5 \mathrm{~min}$ ), the blots were developed using an ECL kit (Amersham Biosciences). The relative intensity of the scanned bands was measured using image analyzing Scion Imaging Software (Scion Corporation, Frederick, MD, USA) based on the surface area and intensity of each band. Test surface area values were compared to those obtained with the control samples.

\section{Statistical Analysis}

Experimental values are given as means \pm SD. The statistical significance of differences between the control values and the test values was evaluated using a one-way ANOVA. Posterior comparisons were performed using Tukey's method. Normality and variance assumptions were verified using the Shapiro-Wilk test and the Brown and Forsythe test, respectively. All of the assumptions were fulfilled. $P$-values were declared significant at 0.05 . The data were analyzed using the SAS version 8.2 statistical package (SAS Institute Inc., Cary, NC, USA).

\section{RESULTS}

\section{Tissue Structure and Cell Morphology}

Histological analyses (Fig. 2) revealed that C. albicans did cause a side effect for both cells and tissue. Although the 2 and $4 \mathrm{~h}$ contact produced no visible damage, and the $8 \mathrm{~h}$ contact produced only slight changes, significant disorganization was observed in the monolayer cultures and tissue after $24 \mathrm{~h}$ of contact (Fig. 2d-f). This was characterized by the presence of a high number of differentiated cells (large cells with faint nuclei, large cytoplasm) in the monolayer cultures (Fig. 2d) and in the upper epithelial layers of the C. albicans-infected tissue (Fig. 2e,f). C. albicans infection

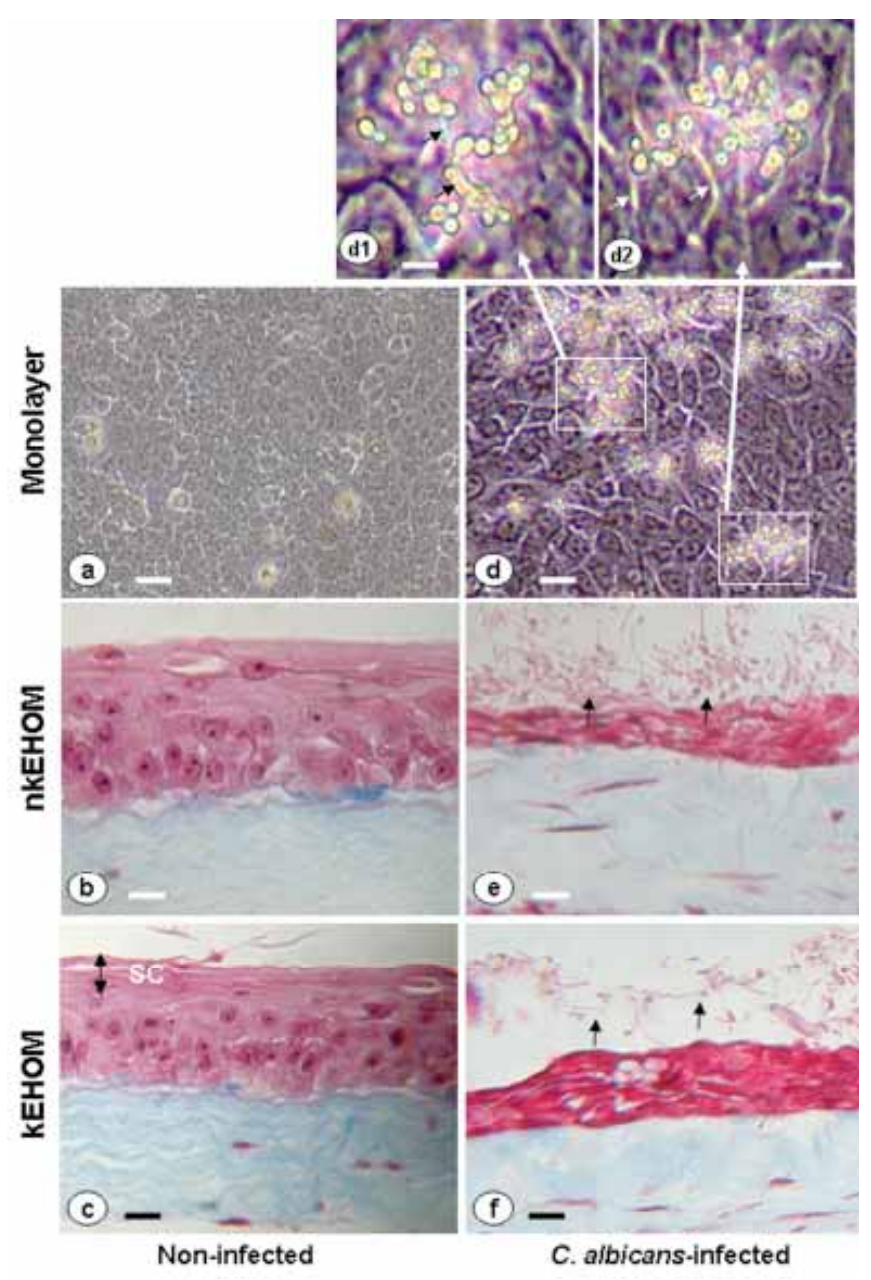

Fig. (2). Cell morphology and histological features of the tissue following infection with C.albicans. The cell morphology and tissue structures were assessed $24 \mathrm{~h}$ post-infection. Monolayer cultures $(\mathbf{a}, \mathbf{d}, \mathbf{d 1}, \mathbf{d 2})$ were observed under an optical microscope. The tissues (b,c,e,f) were stained with Masson's trichrome and observed under an optical microscope. Of interest is the high density of C. albicans hyphal forms in the nkEHOM (arrowhead), compared to the kEHOM (arrowhead). Transition forms are also identified in the monolayer cultures (arrowhead in (d1) and (d2)). Representative photographs are for five different experiments. Scale bars, $50 \mu \mathrm{m}$ for photos (a) to (f), and $100 \mu \mathrm{m}$ for photos (d1) and (d2). $\mathrm{SC}=$ stratum corneum.

also affected the basal layer profile (reduced cell numbers and disorganized structure) basically in the non-keratinized tissue. On the other hand, C. albicans adopted a hyphal form beginning at $8 \mathrm{~h}$ post-infection. The hyphae were in direct contact with the tissue (data not shown). At $24 \mathrm{~h}$ postinfection, the number of C. albicans hyphal forms appeared more significant on the nkEHOM than on the kEHOM (Fig. 2). These data suggest that tissue structure may control C. albicans transition.

\section{Effect of Tissue Keratinization on C. albicans Transition}

As dentures reduce tissue keratinization [22, 23], which may promote $C$. albicans adhesion and transition from blastospore to hyphal form, we used three different models to investigate the effect of tissue stratification (organization of the epithelial tissue on a multilayer structure including the stratum corneoum) on C. albicans transition. As shown in 
Fig. (3), C. albicans adhered to the monolayer and to the EHOMs and changed from blastospore to hyphal form. Following a growth of $2 \mathrm{~h}$ on the monolayer, the proportion of hyphal forms was over $70 \%$, gradually decreasing to approximately $50 \%$ after $24 \mathrm{~h}$. When C. albicans was cultured on the nkEHOM, the proportion of hyphal forms remained under $50 \%$ after $2 \mathrm{~h}$, with no significant changes at 4,8 , and $24 \mathrm{~h}$. The proportion of hyphal forms was even lower on the kEHOM, remaining under $20 \%$ even after $24 \mathrm{~h}$. The degree of transition thus depended on the model. The monolayer promoted $C$. albicans transition, whereas the KEHOM reduced yeast transition. These results are reflected in the proportion of hyphal forms in the culture supernatants (data not shown). Indeed, following counts of the blastospore and hyphal forms of $C$. albicans, the hyphal state reached approximately $60 \%$ two hours post-contact with the monolayer, with no significant changes up to $24 \mathrm{~h}$. The proportion was approximately $20 \%$ in the culture supernatant of the nkEHOM. In the kEHOM, very few if any hyphal forms were present in the supernatant, which supports the findings shown in Fig. (2f). This suggests that compared to the nkEHOM, the kEHOM significantly $(\mathrm{p}<0.05)$ blocked the transition of C. albicans from blastospore to hyphal form.

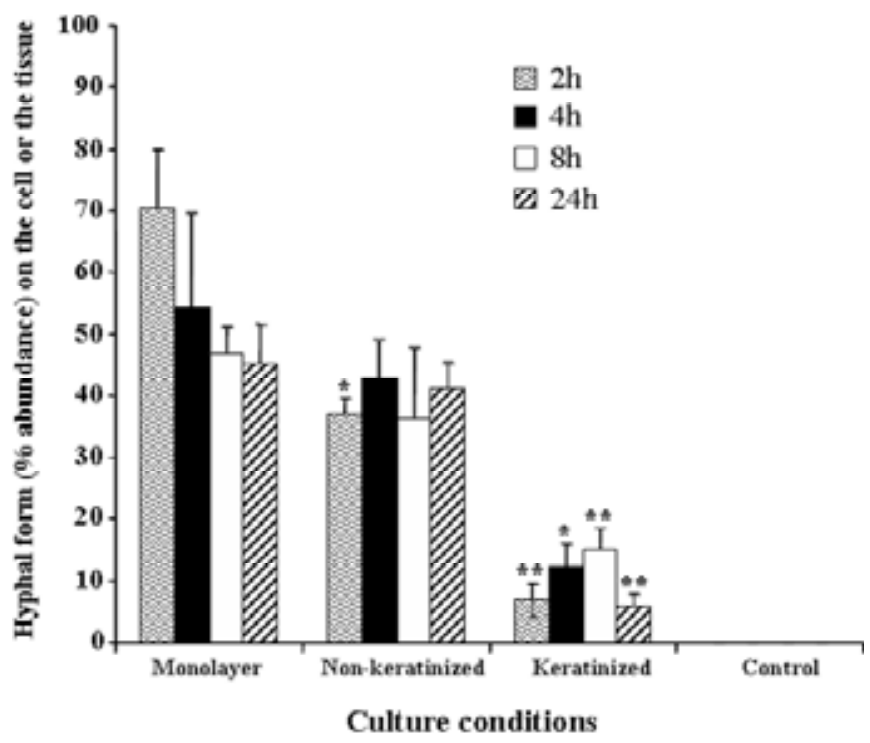

Fig. (3). Proportion of C. albicans hyphal forms following adhesion to epithelial cells and EHOMs. C. albicans was put in contact with oral epithelial cells in a monolayer culture nkEHOM and in kEHOMs for various periods of time. At each time point, epithelial cell and EHOM samples were collected, washed extensively, and lysed, and the number of blastospore and hyphal forms were counted. The percentage $(\%)$ of C.albicans transition was calculated by dividing the number of hyphae by the total number of C. albicans cells $x 100$. Results are the means \pm SD of eight different experiments. The control refers to the percentage of $C$. albicans transition when cultured alone. The results obtained with the three models were statistically compared to the control $(* p<0.05$, $* * \mathrm{p}<0.01)$. The results obtained with the monolayer culture model were also compared with those of the nkEHOM or kEHOMs.

\section{Effect of $C$. albicans on Differentiating Keratin K10 Pro- duction}

We also investigated the effect of C.albicans on K10 production. As shown in Fig. (4), C. albicans significantly $(\mathrm{p}<0.05, \mathrm{p}<0.01)$ promoted K10 production by the epithelial cells in the monolayer. Cell differentiation (K10 production) was initiated at the onset of the infection and was maintained throughout the $24 \mathrm{~h}$ study period. The increase in K10 was confirmed by the presence of differentiating epithelial cells with a large cytoplasm and a faint nucleus. When the kEHOM and nkEHOM were infected with C. albicans, K10 production was significantly reduced $(\mathrm{p} \leq 0.05)$, compared to that of the monolayer. K10 production in the non-keratinized models was significantly $(\mathrm{p}<0.05)$ low, contrasting that produced by the keratinized models. Overall, these results suggest that C. albicans promoted cell differentiation in the non-stratified model and that stratification prevented the disruption of the cell differentiation by $C$. albicans.
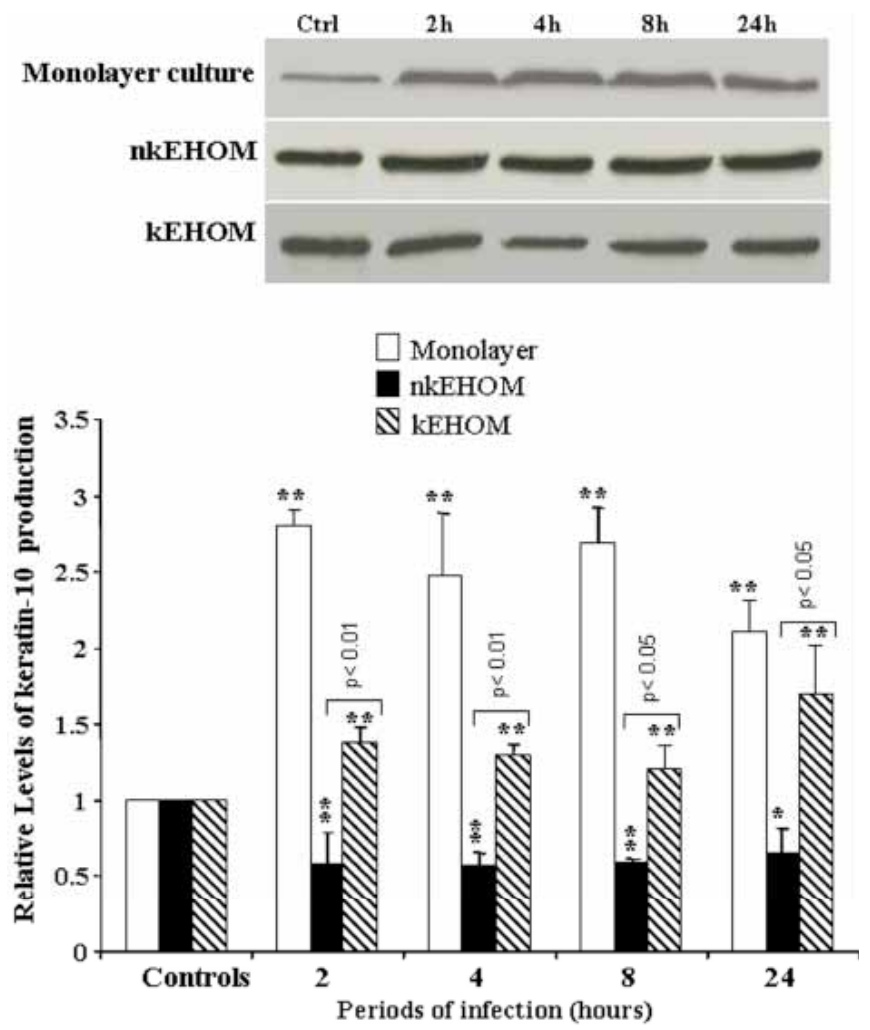

Fig. (4). C. albicans increased K10 production by oral epithelial cells in the monolayer culture and kEHOM models. The total protein $(100 \mu \mathrm{g})$ from lysates of unstimulated (Ctrl) and C. albicans $\left(10^{6} \mathrm{cell} / \mathrm{cm}^{2}\right)$-stimulated oral epithelial cells was analyzed by Western blotting for the presence of K10. Unstimulated epithelial cells and EHOMs were used as controls. Changes in K10 production were determined by band scanning using the Scion Image software program for Windows. Histograms are the means \pm SD of four experiments. The results obtained with the three models were statistically compared to the control $(* \mathrm{p}<0.05, * * \mathrm{p}<0.01)$. The results obtained with the monolayer culture model, nkEHOM, or kEHOMs were also compared.

\section{Effect of C. albicans on Basal Layer Keratin K-14 Pro- duction}

The effect of C. albicans on basal layer K14 production by oral epithelial cells was investigated using the three models. As shown in Fig. (5), the K14 production by the monolayer decreased slightly at $4 \mathrm{~h}$ post-infection, remaining stable thereafter up to $24 \mathrm{~h}$. K14 production by the epithelial cells in the nkEHOM decreased significantly $(\mathrm{p}<0.05)$ at 
$2 \mathrm{~h}$ post-infection and also remained stable up to $24 \mathrm{~h}$. K14 production by the epithelial cells in the kEHOM also decreased significantly $(\mathrm{p}<0.05)$ at $2 \mathrm{~h}$, although this decrease was not significant at $24 \mathrm{~h}$. K14 production significantly $(p<0.01)$ increased in the keratinized model, compared to that in the non-keratinized model. These results suggest that C. albicans had a moderate effect on K14 production by the oral epithelial cells, which, however, depended on the model used.

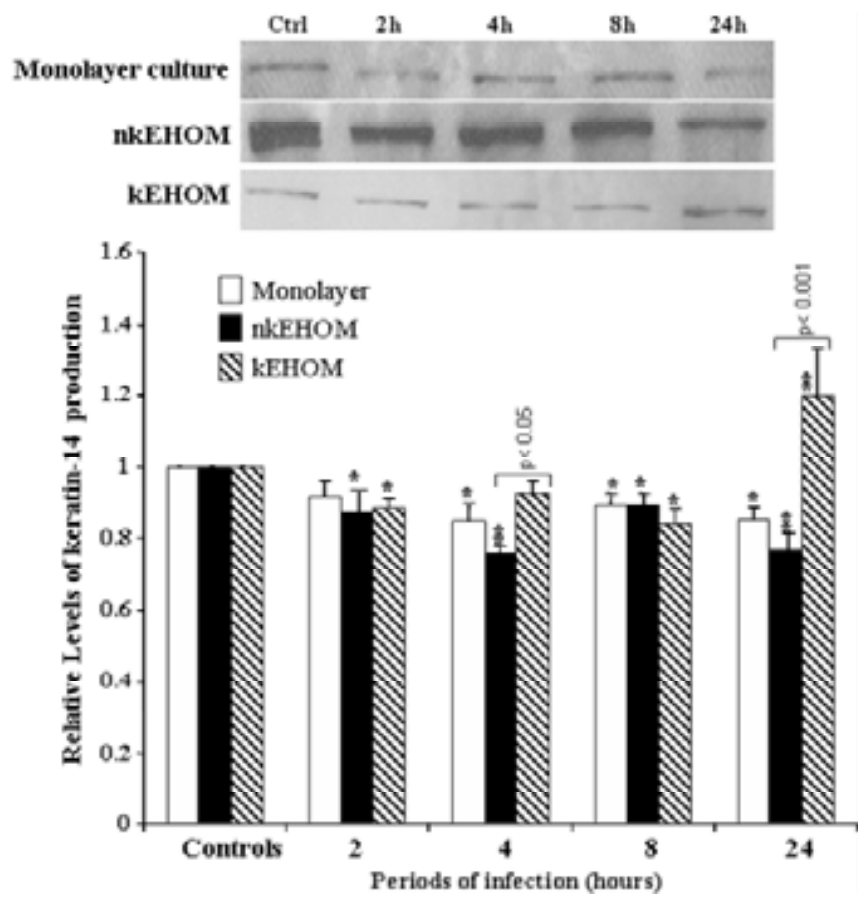

Fig. (5). C. albicans increased K14 production by the oral epithelial cells in the monolayer and $\mathrm{kEHOM}$ models. The total protein $(100 \mu \mathrm{g})$ from lysates of unstimulated $(\mathrm{Ctrl})$ and C. albicans $\left(10^{6}\right.$ cells $\left./ \mathrm{cm}^{2}\right)$-stimulated oral epithelial cells was analyzed by Western blotting for the presence of K14. Unstimulated epithelial cells and EHOMs were used as controls. Changes in K14 production were determined by band scanning using the Scion Image software program for Windows. Histograms are the means \pm SD of four experiments. The results obtained with the three models were statistically compared to the control $(* \mathrm{p}<0.05$, **p $<0.01)$. The results obtained with the monolayer culture model, nkEHOM, or kEHOMs were also compared.

\section{Effect of C. albicans on Proliferating Keratin K16 Pro- duction}

The effect of C. albicans on K16 production was investigated using the three models. As shown in Fig. (6), C. albicans promoted K16 production by the monolayer, with a marked increase at later periods. The effect was even more pronounced in the nkEHOM in contrast to the controls. However, K16 production decreased slightly in the kEHOM. The decease in K16 production was significantly $(\mathrm{p}<0.05)$ more pronounced when comparing the non-keratinized to the keratinized models. These results suggest that $C$. albicans promoted cell proliferation in the nkEHOM and that keratinization prevented cell proliferation in response to the C. albicans infection.
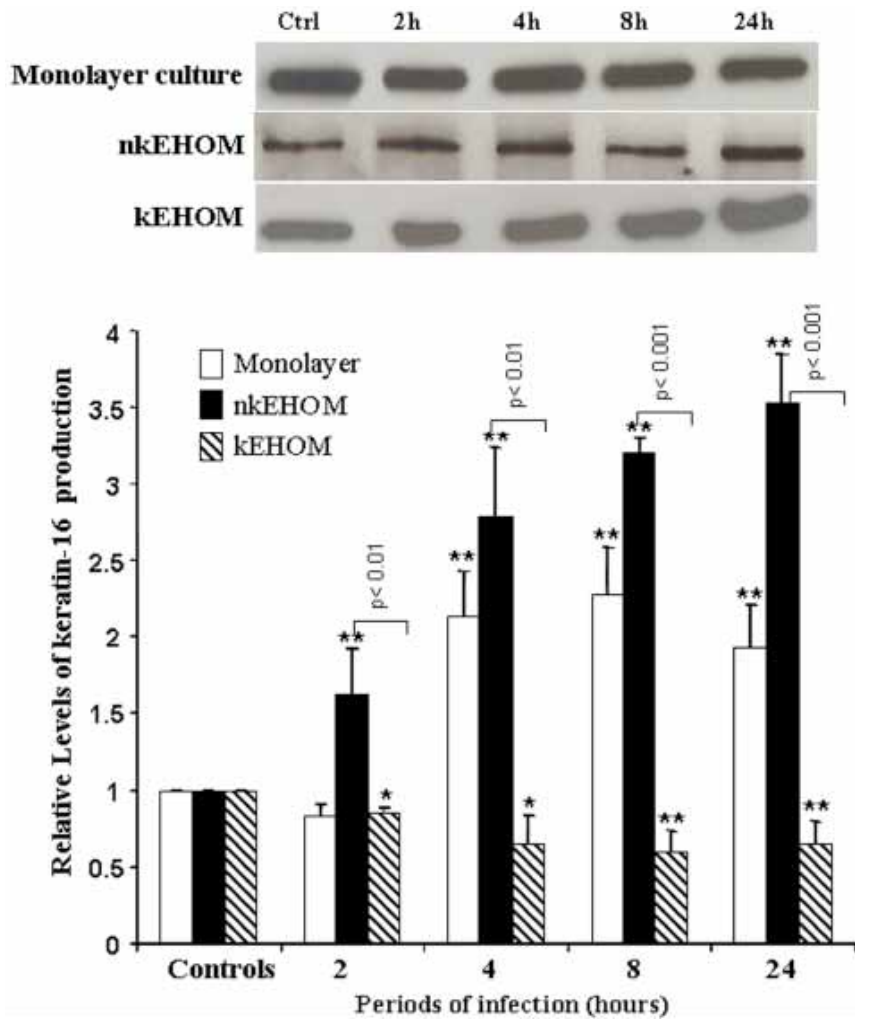

Fig. (6). C. albicans increased K16 production by oral epithelial cells in the monolayer and nkEHOM models. The total protein $(100 \mu \mathrm{g})$ from lysates of unstimulated (Ctrl) and C.albicans $\left(10^{6}\right.$ cells $\left./ \mathrm{cm}^{2}\right)$-stimulated oral epithelial cells was analyzed by Western blotting for the presence of K16. Non-stimulated epithelial cells and EHOMs were used as controls. Changes in K16 production were determined by band scanning using the Scion Image software program for Windows. Histograms are the means \pm SD of four experiments. The results obtained with the three models were statistically compared to the control $(* \mathrm{p}<0.05, * * \mathrm{p}<0.01)$. The results obtained with the monolayer culture model, nkEHOM, or kEHOMs were also compared.

\section{Effect of C. albicans on Fetal Keratin K-19 Production}

The effect of C. albicans on K19 production was investigated using the three models. As shown in Fig. (7), K19 production significantly $(\mathrm{p}<0.01)$ increased in the kEHOM, beginning $2 \mathrm{~h}$ post-contact and continued to augment to $24 \mathrm{~h}$ post-contact. C. albicans had little effect on K19 production by both the monolayer and the nkEHOM. K19 production in the non-keratinized model differed significantly $(\mathrm{p}<0.05)$ from that obtained with the keratinized model. These results suggest that the keratinized layer protected against C. albicans and promoted K19 production.

\section{DISCUSSION}

The oral mucosal epithelium is a barrier to physical, microbial, and chemical agents that may cause local cell injury [32] and is divided into different layers, including the stratum corneum [33]. The disruption of oral mucosal integrity can lead to infections such as denture-associated candidiasis. The oral epithelium of denture-bearing mucosa becomes less keratinized [23], which may allow C. albicans to come into 

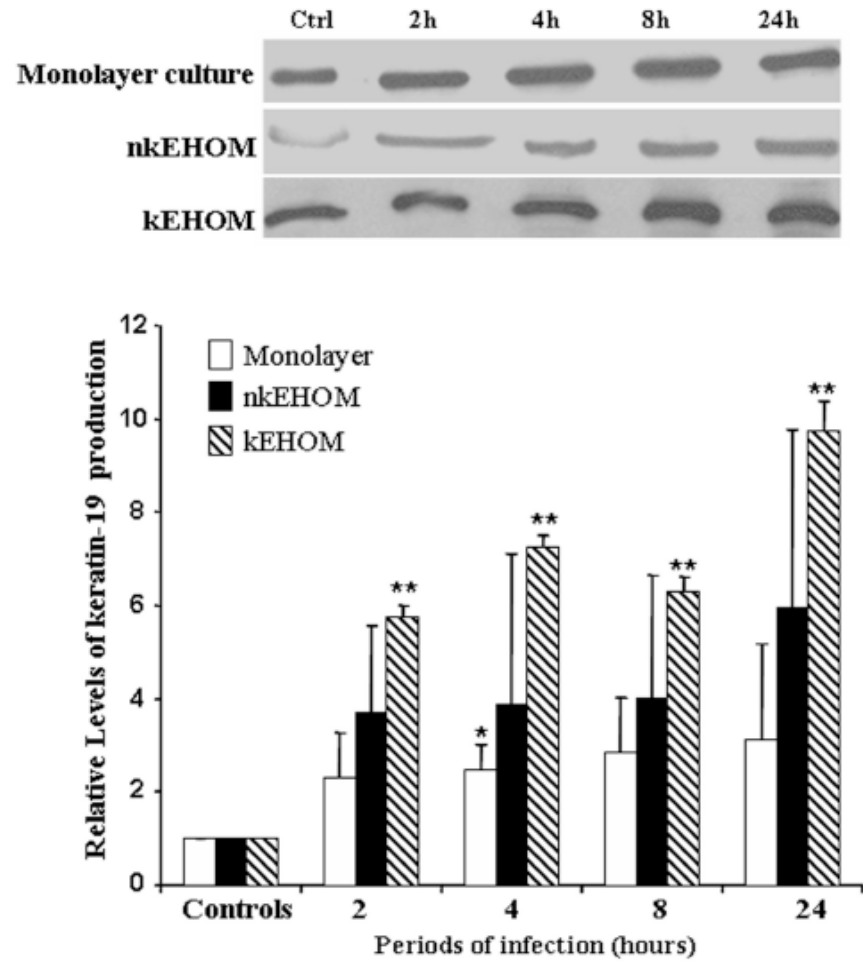

Fig. (7). C. albicans increased K19 production by oral epithelial cells in the monolayer and $\mathrm{kEHOM}$ models. The total protein $(100 \mu \mathrm{g})$ from lysates of non-stimulated (Ctrl) and C. albicans $\left(10^{6}\right.$ cells $\left./ \mathrm{cm}^{2}\right)$ stimulated oral epithelial cells was analyzed by Western blotting for the presence of K19. Non-stimulated epithelial cells and EHOMs were used as controls. Changes in K19 production were determined by band scanning using the Scion Image software program for Windows. Histograms are the means \pm SD of four experiments. The results obtained with the three models were statistically compared to the control $(* \mathrm{p}<0.05, * * \mathrm{p}<0.01)$. The results obtained with the monolayer culture model, nkEHOM, or kEHOMs were also compared.

contact with deeper tissue layers, thereby facilitating its transition and subsequent pathogenicity. To test this hypothesis, three different oral mucosa models were used with varying degrees of tissue stratification and keratinization. We demonstrated for the first time that tissue stratification controls the transition of $C$. albicans from blastospore to hyphal form. The proportion of hyphal forms increased, from $10 \%$ in the stratified $\mathrm{kEHOM}$ to almost $70 \%$ in the monolayer. The tissue found under and around dentures is generally less keratinized and denture stomatitis is frequent (10-75\%) among denture wearers $[22,23,34]$. This may be mimicked by the engineered non-keratinized models showing highly adherent hyphae, compared to the keratinized models.

In the absence of a denture, the oral palate is cornified [33] tissue. C. albicans may adhere to keratinized cells, yet is removed by desquamation which reduces its carriage and controls its pathogenicity [35]. In contrast, the oral tissue under and around dentures is less stratified and less keratinized. The fact that the area of the oral mucosa covered by a total prosthesis is greater than that covered by a partial denture may be an important factor explaining the presence of ulcerative lesions in full denture wearers. Another factor that may promote tissue hyperplasia could be denture pressure [36]. The environment between the denture and the palate may also contribute to the decreased tissue keratinization [37]. When C. albicans adheres to this tissue, it is in direct contact with epithelial cells that secrete certain proteins, which in turn may promote $C$. albicans growth and transition. This hypothesis is supported by the results obtained with the three models used in this study. Complete dentures may contribute to reducing palate stratification in the keratinized cell layer [37], thereby promoting C. albicans adherence [38], which may partly explain the high incidence of oral candidiasis in denture wearers.

To confirm the role of stratified tissue on C.albicans pathogenicity, we investigated the production of various keratins by oral epithelial cells following contact with C. albicans. The epithelial cell monolayer produced greater amounts of differentiating $\mathrm{K} 10$ than did the $\mathrm{kEHOM}$ and nkEHOM following contact with $C$. albicans. This is in agreement with previously reported results indicating that K10 expression varies with cell type [39], developmental stage [40], tissue differentiation [41], and pathological changes [42]. Given the effect of C. albicans on K10 production, we investigated the effect on proliferative and basal layer K14 and showed that the yeast did not affect K14 production. These results are in agreement with those reported by Kellokoski et al. (1991) who reported that oral mucosa biopsies harvested from women with genital human papillomavirus (HPV) infections do not express or produce K14 [43].

While C. albicans had little effect on K14 production, it did increase K16 production in both the monolayer and the nkEHOM model, which displayed a much higher level of organization compared to the monolayer. C. albicans reduced K16 production in the $\mathrm{kEHOM}$, which is in agreement with previously reported results [44]. Our study as well as others [43] suggest that epithelial cell proliferation, and thus K16 production, is promoted during the inflammatory stage of C. albicans infection.

As our models were composed of heterogeneous epithelial cell populations (cells at various stages of proliferation and differentiation), C. albicans may both potentiate the differentiation of epithelial cells in the late proliferative stage as well increase the proliferation rate of proliferating epithelial cells. This may explain the hyperplasia observed in the oral mucosal tissue of patients with oral candidiasis [45]. C. albicans also had an effect on fetal keratin K19 production. The greatest stimulation of K19 production was observed in the kEHOM. As K19-producing cells are in the basal layer, therefore not in contact with $C$. albicans, this suggests the yeast had an indirect effect, possibly due to soluble mediators produced either by upper cell layers that were stimulated by C. albicans, or by the yeast itself. We know that K19 is a sensitive molecule that can be used as a marker for gingival inflammation [46]. PritloveCarson confirmed this by showing that K19 expression is significantly higher in inflamed sulcular epithelium and external oral epithelium than in normal tissue [47]. Our results are thus in agreement with these observations of a link between K19 production and inflammation, such as that observed with denture stomatitis.

In conclusion, this study shows that the transition of C. albicans from blastospore to hyphal form depends on the tissue model. The interaction of C. albicans with epithelial cells and tissue increases the production of proliferating keratins K14, K16, and K19 and differentiating keratin K10. These keratins down-regulate the yeast's proliferation and transition from blastospore to hyphal form. 


\section{ACKNOWLEDGEMENTS}

The authors would like to thank the clinicians of the Faculty of Dental Medicine for collecting the biopsies, and Yakout Mostefaoui for his technical assistance. This study was supported by operating grants from the Fonds de la recherche en santé du Québec (FRSQ), the Fonds Émile-Beaulieu, and the Natural Sciences and Engineering Research Council of Canada (NSERC).

\section{REFERENCES}

[1] Budtz-Jorgensen E. The significance of Candida albicans in denture stomatitis. Scand J Dent Res 1974; 82: 151-90.

[2] Iacopino AM, Wathen WF. Oral candidal infection and denture stomatitis. a comprehensive review. J Am Dent Assoc 1992; 123: 46-51.

[3] Radford DR, Challacombe SJ, Walter JD. Denture plaque and adherence of Candida albicans to denture base materials in vivo and in vitro. Crit Rev Oral Biol Med 1999; 10: 99-116.

[4] Radford DR, Challacombe SJ, Walter JD. Adherence of phenotypically switched Candida albicans to denture base materials. Int J Prosthodont 1998; 11: 75-81.

[5] Daniluk T, Tokajuk G, Stokowska W, et al. Occurrence rate of oral Candida albicans in denture wearer patients. Adv Med Sci 2006; 51: $77-80$.

[6] Ramage G, Tomsett K, Wickes BL, Lopez-Ribot JL, Redding SW. Denture stomatitis: a role for Candida biofilms. Oral Surg Oral Med Oral Pathol Oral Radiol Endod 2004; 98: 53-9.

[7] Bergendal T, Isacsson G. A combined clinical, mycological and histological study of denture stomatitis. Acta Odontol Scand 1983; 41: 3344.

[8] Moskona D, Kaplan I. Oral health and treatment needs in a noninstitutionalized elderly population: experience of a dental school associated geriatric clinic. Gerodontology 1995; 12: 95-8.

[9] Reichart PA, Althoff J. Granular type of denture stomatitis. A scanning electron microscopic study of epithelial surface patterns. Oral Surg Oral Med Oral Pathol 1982; 54: 66-72.

[10] Lo HJ, Kohler JR, DiDomenico B, Loebenberg D, Cacciapuoti A, Fink GR. Nonfilamentous C. albicans mutants are avirulent. Cell 1997; 90: 939-949.

[11] Mitchell AP. Dimorphism and virulence in Candida albicans. Curr Opin Microbiol 1998; 1: 687-692.

[12] Hube B. From commensal to pathogen: stage- and tissue-specific gene expression of Candida albicans. Curr Opin Microbiol 2004; 7: 336341.

[13] Gow NAR, Brown AJP, Odds FC. Fungal morphogenesis and host invasion. Curr Opin Microbiol 2002; 5: 366-371.

[14] Fidel PL Jr. Immunity to Candida. Oral Dis 2002; 8: 69-75.

[15] Niyonsaba F, Hirata M, Ogawa H, Nagaoka I. Epithelial cell-derived antibacterial peptides human beta-defensins and cathelicidin: multifunctional activities on mast cells. Curr Drug Targets Inflamm Allergy 2003; 2: 224-31.

[16] Rouabhia M, Ross G, Page N, Chakir J. Interleukin-18 and gamma interferon production by oral epithelial cells in response to exposure to Candida albicans or lipopolysaccharide stimulation. Infect Immun 2002; 70: 7073-80

[17] Moll R, Franke WW, Schiller DL, Geiger B, Krepler R. The catalog of human cytokeratins: patterns of expression in normal epithelia, tumors and cultured cells. Cell 1982;31: 11-24.

[18] Presland RB, Dale BA. Epithelial structural proteins of the skin and oral cavity: function in health and disease. Crit Rev Oral Biol Med 2000; 11: 383-408.

[19] Richard G, De Laurenzi V, Didona B, Bale SJ, Compton JG. Keratin 13 point mutation underlies the hereditary mucosal epithelial disorder white sponge nevus. Nat Genet 1995; 11: 453-5.

[20] Steinert PM. Structure, function, and dynamics of keratin intermediate filaments. J Invest Dermatol 1993; 100: 729-34.

[21] Bloor BK, Su L, Shirlaw PJ, Morgan PR. Gene expression of differentiation-specific keratins (4/13 and 1/10) in normal human buccal mucosa. Lab Invest 1998; 78: 787-95.
[22] Akal UK, Mocan A, Aydogan S, Oygur T, Bagci L, Camdeviren H. Keratinization of palatal mucosa beneath metal-based removable partial and acrylic-based complete dentures compared with normal palatal mucosa: a clinical, cytological and histological study. J Marmara Univ Dent Fac 1997; 2: 665-72.

[23] Watson IB, MacDonald DG. Oral mucosa and complete dentures. J Prosthet Dent 1982; 47: 133-40.

[24] Clausen H, Moe D, Buschard K, Dabelsteen E. Keratin proteins in human oral mucosa. J Oral Pathol 1986; 15: 36-42.

[25] Lindholm, K, Hakala PE, Makila E. Leukocyte count and keratinization of the palatal denture-bearing mucosa. J Prosthet Dent 1982; 47: 440-4.

[26] Rouabhia M, Deslauriers N. Production and characterization of an in vitro engineered human oral mucosa. Biochem Cell Biol 2002; 80: 18995.

[27] Izumi K, Terashi H, Marcello CL, Feinberg SE. Development and characterization of a tissue-engineered human oral mucosa equivalent produced in a serum-free culture system. J Dent Res 2000; 79: 798-805.

[28] Rouabhia M. In vitro production and transplantation of immunologically active skin equivalents. Lab Invest 1996; 75: 503-17.

[29] Beausejour A, Grenier D, Goulet JP, Deslauriers N. Proteolytic activation of the interleukin- $1 ß$ precursor by Candida albicans. Infect Immun 1998; 66: 676-681.

[30] Claveau I, Mostefaoui Y, Rouabhia M. Basement membrane protein and matrix metalloproteinase deregulation in engineered human oral mucosa following infection with Candida albicans. Matrix Biol 2004; 23: 477-86.

[31] Mostefaoui Y, Claveau I, Rouabhia M. In vitro analyses of tissue structure and interleukin-1beta expression and production by human oral mucosa in response to Candida albicans infections. Cytokine 2004; 25: 162-71.

[32] Presland RB, Jurevic RJ. Making sense of the epithelial barrier: what molecular biology and genetics tell us about the functions of oral mucosal and epidermal tissues. J Dent Educ 2002; 66: 564-74.

[33] Squier CA, Kremer MJ. Biology of oral mucosa and esophagus. J Natl Cancer Inst Monogr 2001; 29: 7-15.

[34] Odds FC. Mycology in oral pathology. Acta Stomatol Belg 1997; 94 : 75-80.

[35] Epstein JB, Truelove EL, Izutzu KT. Oral candidiasis: pathogenesis and host defense. Rev Infect Dis 1984; 6: 96-106.

[36] Budtz-Jorgensen E. Oral mucosal lesions associated with the wearing of removable dentures. J Oral Pathol 1981; 10: 65-80.

[37] Coelho CM, Sousa YT, Dare AM. Denture-related oral mucosal lesions in a Brazilian school of dentistry. J Oral Rehabil 2004; 31: 135-9.

[38] Bulad K, Taylor RL, Verran J, McCord JF. Colonization and penetration of denture soft lining materials by Candida albicans. Dent Mater 2004; 20: 167-75.

[39] Quinlan RA, Schiller DL, Hatzfeld M, et al. Patterns of expression and organization of cytokeratin intermediate filaments. Ann N Y Acad Sci 1985; 455: 282-306.

[40] Banks-Schlegel SP. Keratin alterations during embryonic epidermal differentiation: a presage of adult epidermal maturation. J Cell Biol 1982; 93: 551-559.

[41] Mackenzie IC, Hill MW. Connective tissue influences on patterns of epithelial architecture and keratinization in skin and oral mucosa of the adult mouse. Cell Tissue Res 1984; 235: 551-9.

[42] Kellokoski J, Syrjanen S, Tosi P, Cintorino M, Leoncini P, Syrjanen K. Cytokeratin pattern in normal and HPV infected oral mucosa in women with genital HPV infections. J Oral Pathol Med 1991; 20: 26-31.

[43] Katou F, Motegi K, Tagami H, Shirai N, Echigo S, Nagura H. Unique inflammatory features noted in intraorally transferred skin flaps: correlation with Candida albicans infection. Oral Surg Oral Med Oral Pathol Oral Radiol Endod 1999; 87: 676-84.

[45] Pabuccuoglu U, Tuncer C, Sengiz S. Histopathology of candidal hyperplastic lesions of the larynx. Pathol Res Pract 2002; 198: 675-8.

[46] Sawaf MH, Ouhayoun JP, Forest N. Cytokeratin profiles in oral epithelial: a review and a new classification. J Biol Buccale 1991; 19: 187-98.

[47] Pritlove-Carson S, Charlesworth S, Morgan PR, Palmer RM. Cytokeratin phenotypes at the dento-gingival junction in relative health and inflammation, in smokers and nonsmokers. Oral Dis 1997; 3: 1924. 